\title{
Influence of Surface Morphology on Electrophysical Properties of PbTe: Sb Films
}

\begin{abstract}
Vasyl Stefanyk Precarpathian National University ", Ivano-Frankivsk, Ukraine, saliyyaroslav@gmail.com
The electrophysical properties of polycrystalline doped semiconductor thin films PbTe: Sb deposited on mica and sital (glass based ceramic) substrates are considered. The thickness dependences of carrier mobility, of Hall coefficient and of Seebeck coefficient, and the correlations between these parameters for films deposited on different substrate materials were studied. The peculiarities of growth of thin films and their structural parameters are analyzed taking into account the features of the 'substrate - film' boundary section.
\end{abstract}

Key words: $\mathrm{PbTe}: \mathrm{Sb}$, thin films, electrophysical properties, growth of films.

Received 7 June 2021; Accepted 23 June 2021.

\section{Introduction}

Semiconductor structures based on lead telluride films are often used for manufacturing of the detectors and radiation sources of the IR-waves of the optical spectrum $[1,2]$ and for mid-temperature $(500-850 \mathrm{~K})$ thermoelectric energy converters based them [3,4]. The study of dimensional and quantum effects causes to development of structures with hundreds of atomic diameters [5-7].

The sufficient attention was paid to the study of surface morphology, electrophysical properties of PbTe thin films [8-11] and modification of electronic and phonon crystalline subsystems by doping with antimony $[12,13]$. But the question of correlation of the thickness dependences of the surface morphological characteristics of lead and electrophysical properties found in [9] remained open.

In $[9,14]$ revealed an abrupt qualitative change in the size, shape and density of nanoobjects on the surface with a change in the thickness of films. Such change is associated with the transition from hetero-epitaxial, that characterized by mechanical stresses due to differences in both structures and coefficients of thermal expansion of condensates and substrates, to homo - epitaxial growth of PbTe: $\mathrm{Sb}$ film in the absence of these stresses.

In this paper tested the hypothesis of the correlation of morphological and electrophysical properties based on the analysis of the data of [15], which presents both morphological and electrophysical characteristics of PbTe: Sb films of different thickness deposited on two types of substrates: sital (ceramic based glass) and mica.

\section{Experiment}

In $[4,5,8]$ it was found that bulk lead telluride with an antimony content of 1 at. $\%$ have the best thermoelectric parameters. Thin films of $\mathrm{PbTe}: \mathrm{Sb}$ were deposited using of PVD technology by open evaporation in vacuum on sital (ceramic glass) substrates and fresh chips (0001) of muscovite mica. The thickness of thin films up to $2.3 \mu \mathrm{m}$ were obtained at an evaporator temperature of $970 \mathrm{~K}$ and a deposition temperature of $470 \mathrm{~K}$.

The morphology of the film surface was studied by AFM images (Nanoscope III a Dimention 3000). Electrophysical measurements were performed at room temperature by the 6-probe method in constant electric and magnetic fields. 


\section{Results of the research}

AFM images shown that a thickness of $0.7 \mu \mathrm{m}$ divides the films deposited on the sital into two groups. In the group of the films of smaller thickness, the lateral dimensions of surface objects are $\mathrm{d}=20-30 \mathrm{~nm}$ and height $\mathrm{h}=5-20 \mathrm{~nm}$, in the group of films of thicker lateral dimensions $-\mathrm{d} \sim 180 \mathrm{~nm}$ and height $\mathrm{h} \sim 140 \mathrm{~nm}$.

As shown in Fig. 1, 2, under all technological modes, the nucleation of nanostructures is realized by the Volmer-Weber mechanism [16]. Namely, the columnar pyramidal structures are formed, the size and structural shapes of which are determined by temperature and deposition time. As the deposition time increases, the size of the surface nanoobjects increases in both the normal and lateral directions. As shown in $[17,18]$ the dominant is the diffusion mechanism of nanocrystal formation. Accordingly, diffusion in the vapor phase is responsible for the formation of faceted nucleus. As the deposition time increases, the mechanisms of reevaporation begin to be realized and the start the stage of aggregation of objects on the surface, which leads to their merging and less structural perfection.

Similarly, for films deposited on mica it was found that the thickness of $\sim 1 \mu \mathrm{m}$ also divides the films into

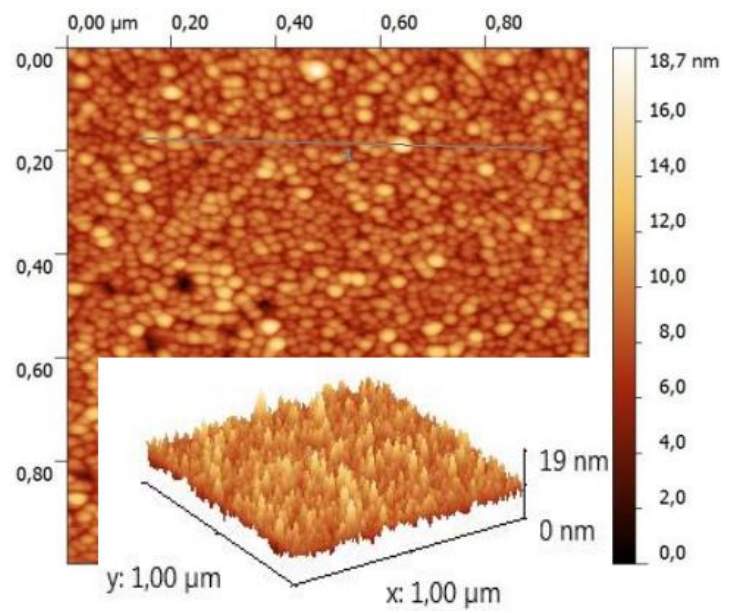

a) two groups. In the group of films of smaller thickness, the lateral dimensions of objects on the film surface are $\mathrm{d}=70-100 \mathrm{~nm}$ and height $-\mathrm{h}=30-50 \mathrm{~nm}$, for films of the group of thicker thickness, the lateral dimensions are $\mathrm{d} \sim 220 \mathrm{~nm}$ and height $\mathrm{h} \sim 160 \mathrm{~nm}$.

It turned out that for both types of substrates in the first group are not faceted convex objects in the shape of hemispheres, and in the second group - the faceted objects in the shape of pyramids [15].

Due to the fact that the surface of the film of smaller thickness reflects the layer of the internal structure of the film of greater thickness, we can conclude about the possibility of studying the properties of the film with depth. In case that of certain shape of surface objects are observed on the surface of a thinner film, they are embedded in thicker film. The surface of these objects is a source of scattering centers for free charge carriers, so we should expect a qualitative change in the thickness dependences of the kinetic parameters when passing through the characteristic film thickness. But a significant quantitative change should not be expected.

The division into two groups is observed on the graphically dependence of the carrier mobility, the Hall constant and the Seebeck coefficient on the film thickness (Fig. 3).

Comparing the carrier mobility in films deposited on different substrates, was shown that the course of the

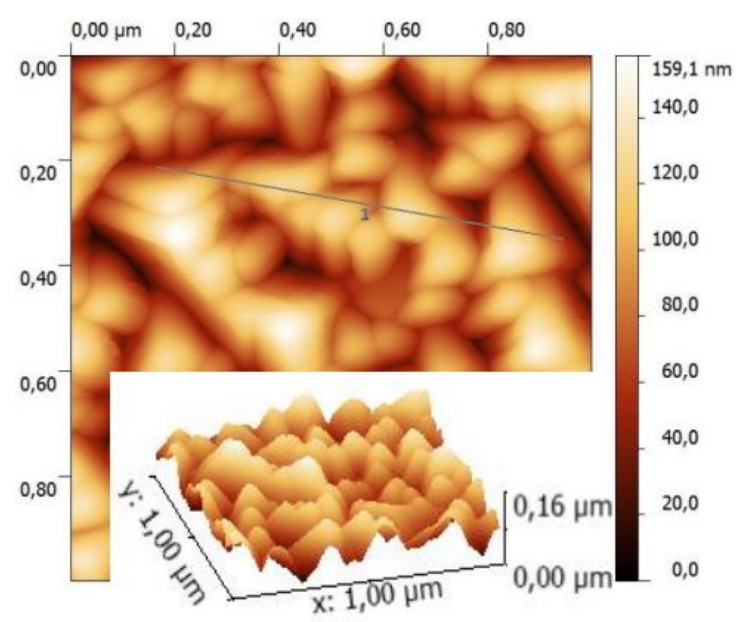

б)

Fig. 1. AFM images of PbTe:Sb films, deposited on (0001) mica substrate at different time of deposition $\tau$,c:

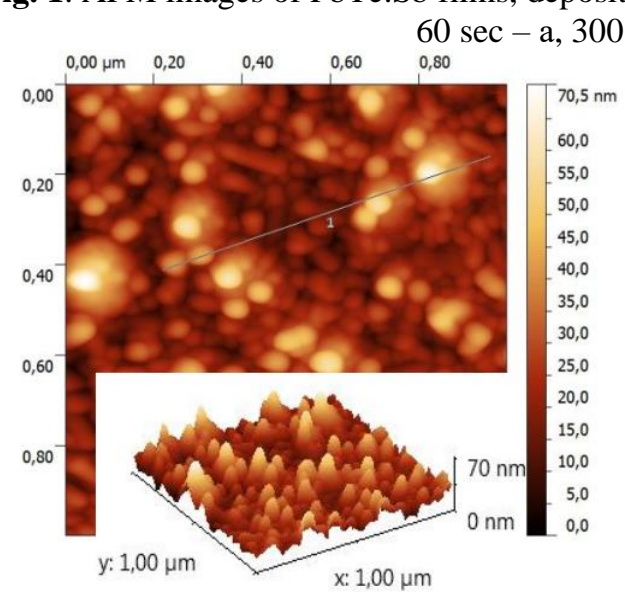

a)

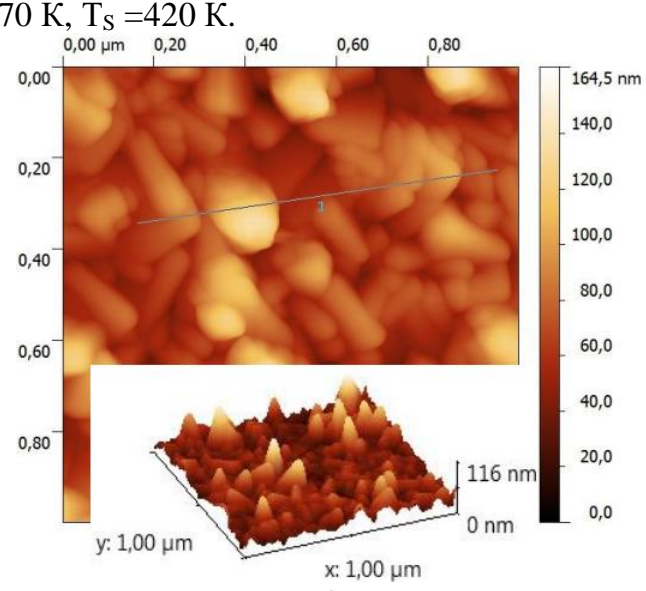

б)

Fig. 2. AFM images of PbTe:Sb films, deposited on sital substrate at different time of deposition $\tau$,c: $40 \mathrm{sec}-\mathrm{a}, 210 \mathrm{sec}-\mathrm{b} ; \mathrm{Te}=970 \mathrm{~K}, \mathrm{~T}_{\mathrm{S}}=470 \mathrm{~K}$. 
thickness dependence for thick films does not depend on the type of substrate. However, the Seebeck coefficient for sital-deposited films is systematically higher than for mica-deposited films. In both graphs there is a decrease in the $S$ value with increasing of film thickness.

For a certain film thickness on the $\mu(\mathrm{D})$ dependence was observe a breaking of monotonic growth, for $R_{H}(D)$ - the region of minimum, and for $S(D)$ - a step on the descending curve (Fig. 3). Note that the characteristic thickness for films deposited on mica is greater than for films deposited on the sital. That is, the effect of the mica substrate is more general with the thickness of the growing crystalline film than with the sital. This is confirmed by AFM studies, that the objects on the surface of the films deposited on sital substrate are less massive than on the surface of the films deposited on mica substrate.

\section{Analysis of results}

The Sondheimer's theory [19] use to establish more basic statements than only description of the experimental thickness dependences of electrophysical parameters. According to this theory, the dependence of the carrier mobility due the film thickness $\mu(D)$ has the form:

$$
\mu(D)=\mu_{\infty}(1-3 \lambda(1-p) / 8 D),
$$

where $\mu_{\infty}$ is the carrier mobility in the sample of large thickness, $\lambda$ is the mean free path of the carriers, $p$ is the coefficient of specular reflection of the surface.

Eq. (1) can be rewritten in an approximate form with 2 parameters:

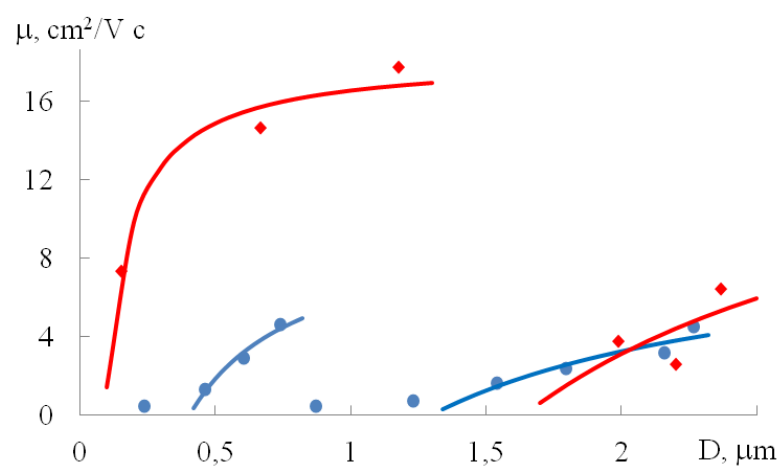

a)

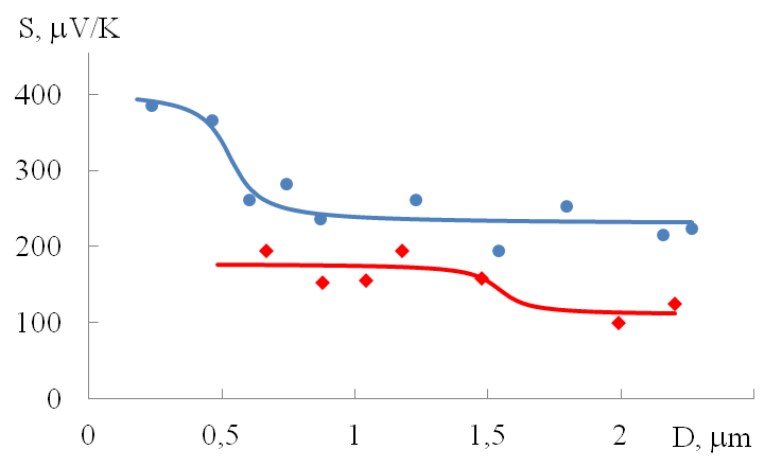

c)

$$
\mu(D)=\mu_{\infty}\left(1-\mathrm{D}^{*} / D\right),
$$

where $\mathrm{D}^{*}=3 \lambda(1-p) / 8$.

Approximately, two areas of the increasing of the experimental dependence of carrier mobility deposited film on the sital on the thickness (Fig. 3). The following approximation parameters of the $\mu(\mathrm{D})$ analytical dependences (2) obtained:

$$
\mu_{\infty I}=5 \mathrm{~cm}^{2} / \mathrm{V} \mathrm{c}, \quad \mathrm{D}^{*}{ }_{I}=0,2 \mu \mathrm{m},
$$

and $\mu_{\infty I I}=6 \mathrm{~cm}^{2} / \mathrm{V} \mathrm{c}$,

$$
\mathrm{D}^{*}=0,9 \mu \mathrm{m} \text {. }
$$

Such approximation parameters for thin films deposited on mica substrate were following:

$$
\begin{gathered}
\mu_{\infty I}=18 \mathrm{~cm}^{2} / \mathrm{V} \mathrm{c}, \quad \mathrm{D}^{*}{ }_{I}=0,1 \mu \mathrm{m}, \\
\text { and } \mu_{\infty I I}=17 \mathrm{~cm}^{2} / \mathrm{V} \mathrm{c}, \quad \mathrm{D}^{*}{ }_{I I}=1,6 \mu \mathrm{m} .
\end{gathered}
$$

In the case $p=0$, which corresponds to diffuse scattering, the mean free path will be approximately 3 times greater than $D^{*}$.

It is shown that the parameter $\mu_{\infty}$ is the same for both sections of the thickness, but $\mathrm{D}^{*}$ for films deposited on the sital substrate differs by $\sim 4$ times, and for films deposited on mica substrate differs by $\sim 16$ times. The values of $\mu \infty$ for mica films are $\sim 3$ times larger than for sieve films.

It should be noted that the performed approximation is not clear due to the significant deviation of the experimental points from the proposed dependence, as well as with inadequately small values of $\mu_{\infty}$ and large values of $\mathrm{D}^{*}$.

The dissimilarity of experimental points relative to formally selected smooth curves, that not provided with a theoretical justification, is observed in other curves (Fig. 3). It may be due to the weak technological

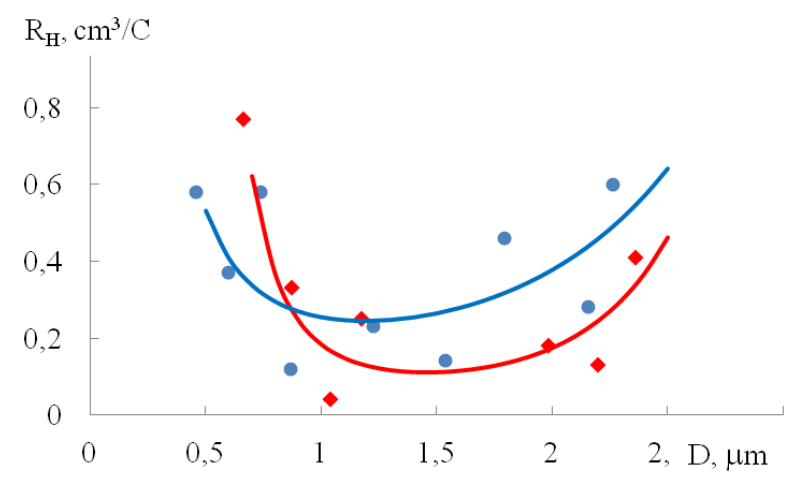

b)

Fig. 3. The thickness dependence of the carrier mobility, Hall constant and the Seebeck coefficient for PbTe: $\mathrm{Sb}$ films deposited on sital (blue circles) and mica (red diamonds). 
controllability of the deposition process of the films. The improbability of the parameter $\mathrm{D}^{*}$ of proposed approximation indicates the relationship of the carrier mobility with another characteristic size. Thus, the heights of surface objects increase linearly with the film thickness. The coefficient of proportionality is $1 / 50$. Thus, we obtain a real value for the mean free path, which will correspond to 40 - $60 \mathrm{~nm}$ after changing the scale of the abscissa axis by 50 times. The dissimilarity of kinetic parameters will be associated with the dissimilarity of the characteristic size of objects, and small values of carrier mobility for high defect objects and the presence of spaces between objects.

Therefore, it can conclude that the morphology of film surface influence on its electrophysical properties.

To avoid a clear connection between the electrophysical parameters and the sizes of the surface objects, were find the correlations between these parameters. In this case, the parameters that are measured independently for an investigated film and are included in the definition of thermoelectric power, namely the Seebeck coefficient $S$ and specific conductivity $\sigma$ were consider.

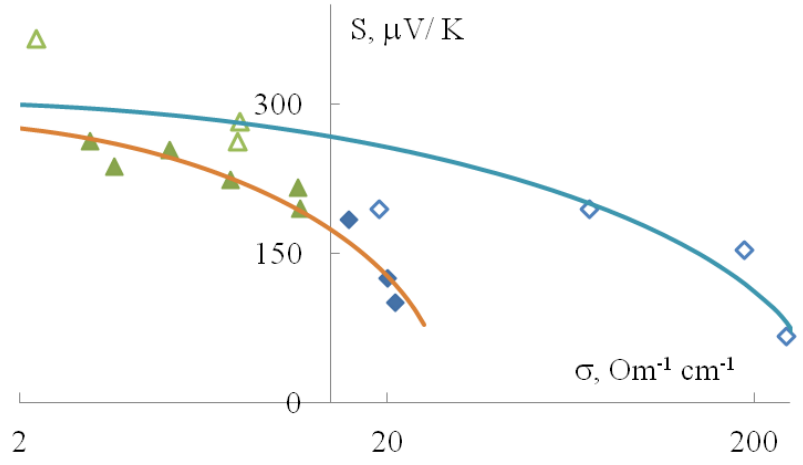

Fig. 4. Correlation between Seebeck coefficient $S$ and specific conductivity $\sigma$. Triangles correspond to films deposited on the sital substrate, rhombuses - correspond to films deposited on mica substrate. Transparent cursors correspond to group of thin films, filled - to a group of thick films.

In Figure 4 shown the experimental points in coordinates $\sigma-\mathrm{S}$. The films deposited on the mica substrate have a higher electrical conductivity (rhomb), and the films deposited on the sital substrate have a higher Seebeck coefficient (triangles). The solid lines correspond to the correlation dependences among thick and thin films. The anti-correlation character of $S$ and $\sigma$ is visible, which leads to the appearance of a nonmonotonic correlation between $S^{2} \sigma$ and $\sigma$ (Fig. 5). In
Fig. 5 was observe that the correlation curve is higher for thin films than for thick films, and a maximum is observed on both curves, which is an order of magnitude higher for thin films in compare to thick films.

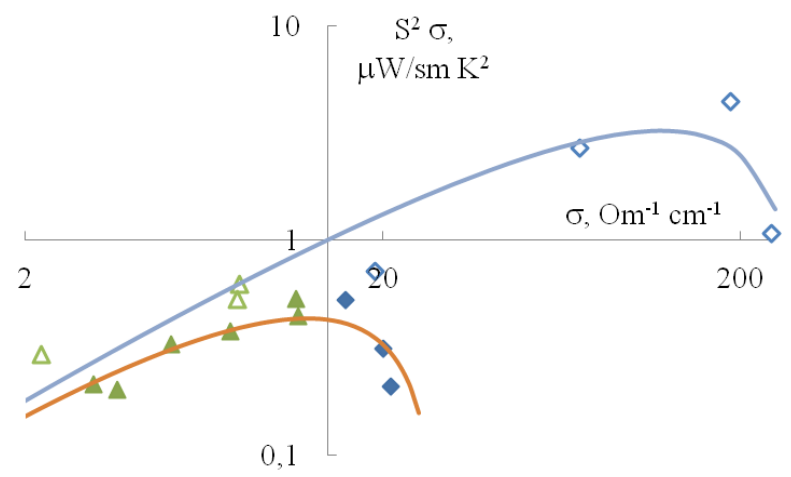

Fig. 5. Correlation between thermoelectric power $S^{2} \sigma$ and specific conductivity $\sigma$. Designation are similar to fig. 3 .

\section{Conclusions}

The deposition of PbTe: Sb films on mica substrate caused to form of polycrystalline films that are electrophysically more perfect than films when deposited on sital substrates, which are amorphous up to certain film thickness, and then polycrystalline.

Thin films grown on mica substrate are more perfect than thick films. Epitaxial reconstitution of mica structure by lead telluride promotes the adjustment growth of tense objects in the surface of PbTe film, and after stress relief the disorientation between the crystallites increases.

The transverse size of the objects increase with the film thickness changes, and the curvature of the boundary decreases. The film will more perfect. The monotonic growth is interrupted by the change of the phase state at the transition from amorphous to crystalline state for films deposited on sital substrate, as well as from the stressed adjustment to the unstressed un adjustment state for the films deposited on the mica substrate.

Saliy Ya.P. - Professor, Ph.D., Professor of the Department of Solid State Physics and Chemistry;

Nykyruy L.I. Professor, Ph.D., Professor of the Department of Solid State Physics and Chemistry.

[1] H. Burkhard, G. Bauer, \& A. Lopez-Otero, Solid State Communications 18(7), 773 (1976); https://doi.org/10.1016/0038-1098(76)90201-5.

[2] A.V. Dmitriev, \& I.P. Zvyagin, $\quad$ Physics-Uspekhi $53(8), \quad 789 \quad$ (2010); https://doi.org/10.3367/UFNe.0180.201008b.0821.

[3] B. Dzundza, L. Nykyruy, T. Parashchuk, E. Ivakin, Ya. Yavorsky, L. Chernyak, \& Z. Dashevsky, Physica B: Condensed Matter. 588, 412178 (2020); https://doi.org/10.1016/j.physb.2020.412178.

[4] Z.H. Dughaish, Physica B: Condensed Matter, 322(1-2), $205 \quad$ (2002); https://ui.adsabs.harvard.edu/link_gateway/2002PhyB..322..205D/doi:10.1016/S0921-4526(02)01187-0.

[5] S.P. Zimin, E.S. Gorlachev, Nanostructured lead chalcogenides: monograph (YarSU, Yaroslavl, 2011). 
[6] Ya. P. Saliy, D.M. Freik, I.K. Yurchyshyn, \& I.M. Freik, J. Nano-and Electronic Physics, 5(3), 03038 (2013); https://jnep.sumdu.edu.ua/download/numbers/2013/3/articles/en/jnep_eng_2013_V5_No3_03038_Saliy.pdf.

[7] L. Nykyruy, M. Ruvinskiy, E. Ivakin, O. Kostyuk, I. Horichok, I. Kisialiou \& A. Hrubyak, Physica E: Lowdimensional systems and nanostructures 106, 10 (2019); https://doi.org/10.1016/j.physe.2018.10.020.

[8] J.P. Heremans, C.M. Thrush, \& D.T. Morelli, Physical Review B, 70(11), 115334 (2004); https://doi.org/10.1103/PhysRevB.70.115334.

[9] Ya. Saliy, M. Ruvinskiy, \& L. Nykyruy, Modern Physics Letters B 31(03), 1750023 (2017); https://doi.org/10.1142/S0217984917500233.

[10] B. Naidych, T. Parashchuk, I. Yaremiy, M. Moyseyenko, O. Kostyuk, O. Voznyak, \& L. Nykyruy, Journal of Electronic Materials 50(2), 580 (2021); https://doi.org/10.1007/s11664-020-08561-5.

[11] Ya. P. Saliy, B.S. Dzundza, I.S. Bylina, \& O.B. Kostyuk, Journal of nano-and electronic physics 8(2), 2045 (2016).

[12] T. Parashchuk, I. Horichok, A. Kosonowski, O. Cherniushok, P. Wyzga, G. Cempura, \& K.T. Wojciechowski, Journal of Alloys and Compounds 860, 158355 (2021); https://doi.org/10.1016/j.jallcom.2020.158355.

[13] C. Krataitong, K. Srichai, \& A. Tubtimtae, Materials Letters, 285, 129085 (2021); https://doi.org/10.1016/j.matlet.2020.129085.

[14] Saliy, Y. P., \& Yavorskyi, R. S. (2019). The redistribution modeling of implanted impurity stimulated by vacancies. Materials Today: Proceedings 35(4), 576-578 (2021); https://doi.org/10.1016/j.matpr.2019.11.017.

[15] D.M. Freik, S.I. Mudryi, I.V. Gorichok, R.O. Dzumedzey, O.S. Krynytskyi, \& T.S. Lyuba, Ukrainian Journal of Physics 59(7), 706 (2014); https://doi.org/10.15407/ujpe59.07.0706.

[16] V.A. Shchukin, D. Bimberg, Rev. Mod. Phys. 71, 1125 (1999); https://doi.org/10.1103/RevModPhys.71.1125.

[17] D.M. Freik, Y. P. Saliy, I.M. Lishchynskyy, V.V. Bachuk, \& N.Y. Stefaniv, Journal of Nano-and Electronic Physics 4(2), 2011 (2012).

[18] A.F. Craievich, O.L. Alves, \& L.C. Barbosa, Journal of Applied Crystallography 30(5), 623 (1997); https://doi.org/10.1107/S0021889897001799.

[19] E.H. Sondheimer, Adv. Phys. 1, 1 (1952); https://doi.org/10.1080/00018735200101151.

\author{
Я.П. Салій, Л.І. Никируй
}

\title{
Вплив морфології поверхні на електрофізичні властивості плівок PbTe:Sb
}

\author{
Прикарпатський національний університет імені Василя Стефаника", Івано-Франківськ, Украӥна, \\ saliyyaroslav@gmail.com
}

\footnotetext{
Розглянуто електрофізичні властивості полікристалічних легованих напівпровідникових тонких плівок $\mathrm{PbTe:Sb}$, осаджених на підкладки слюди та ситалу. Досліджено товщинні залежності рухливості носіїв заряду, коефіцієнта Холла та коефіцієнта Зеєбека та кореляції між цими параметрами для плівок, осаджених на різні матеріали підкладки. Проаналізовано особливості росту тонких плівок та їх структурну досконалість із врахуванням особливостей межі розділу «підкладка - плівка».

Ключові слова: $\mathrm{PbTe}: \mathrm{Sb}$, тонкі плівки, електричні властивості, ріст плівки.
} 